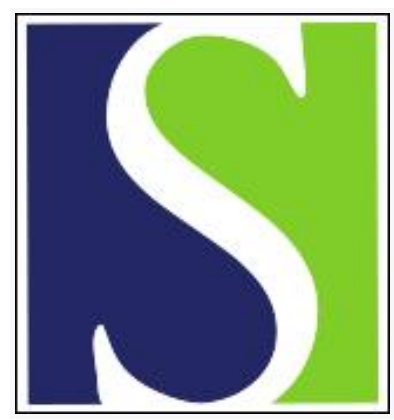

Scand J Work Environ Health 2013;39(2):195-203

https://doi.org/10.5271/sjweh.3324

Published online: 02 Oct 2012, Issue date: 01 Mar 2013

Joint effects of job strain and road-traffic and occupational noise on myocardial infarction

by Selander J, Bluhm G, Nilsson M, Hallqvist J, Theorell T, Willix P, Pershagen $\mathrm{G}$

Affiliation: Institute of Environmental Medicine, Unit of Occupational Medicine, Karolinska Institutet, Norrbacka building 3rd floor, SE-171 76 Stockholm, Sweden. jenny.selander@ki.se

Refers to the following text of the Journal: 2007;33(6):470-478

The following article refers to this text: 2021;47(1):33-41

Key terms: cardiovascular disease; environmental factor; ischemic heart disease; job exposure matrix; job strain; joint effect; myocardial infarction; noise; occupational noise; residential factor; road-traffic noise; stress; work-related factor

This article in PubMed: www.ncbi.nlm.nih.gov/pubmed/23032870 


\title{
Joint effects of job strain and road-traffic and occupational noise on myocardial infarction
}

\author{
by Jenny Selander, MSc, PhD, ${ }^{1}$ Gösta Bluhm, MD, PhD, ${ }^{1}$ Mats Nilsson, MSc, PhD, ${ }^{2}$ Johan Hallqvist, MD, \\ PhD, ${ }^{3}$ Töres Theorell, MD, PhD, ${ }^{4}$ Pernilla Willix, MSc, ${ }^{5}$ Göran Pershagen, MD, PhD ${ }^{1}$
}

\begin{abstract}
Selander J, Bluhm G, Nilsson M, Hallqvist J, Theorell T, Willix P, Pershagen G. Joint effects of job strain and road-traffic and occupational noise on myocardial infarction. Scand J Work Environ Health. 2013;39(2):195-203. doi:10.5271/sjweh.3324
\end{abstract}

Objectives The aim of this study was to assess the joint effect of job strain and both road-traffic and occupational noise on myocardial infarction (MI).

Method We conducted a population based case-control study on first time MI in Stockholm County during 1992-1994. Participants answered a questionnaire and underwent a physical examination. Residential road-traffic noise exposure was based on residential history combined with information on traffic intensity and distance to nearby roads. Occupational noise exposure was assessed by occupational history combined with a job-exposure matrix derived from measurements. Job strain was based on questions regarding psychological demands and decision latitude. A total of 3050 study participants (1252 cases and 1798 controls) were included in the study.

Results An increased risk of MI was indicated among participants exposed to road-traffic noise [odds ratio (OR) 1.23, 95\% confidence interval (95\% CI) 1.01-1.51], occupational noise (OR 1.17, 95\% CI 0.98-1.41) and job strain (OR 1.39, 95\% CI 1.17-1.65). Participants exposed to one, two, or three of these factors showed an increased risk (OR 1.16, 95\% CI 0.97-1.40, OR 1.57, 95\% CI 1.24-1.98, and OR 2.27, 95\% CI 1.41-3.64, respectively). Exposure to two or three of these factors occurred among about $20 \%$ of the controls.

Conclusion Our results indicate that exposure to a combination of noise exposure and job strain increases the risk of MI substantially. Such exposures affect a considerable part of the population, which has relevance for prioritization of preventative measures.

Key terms cardiovascular disease; environmental factor; ischemic heart disease; job exposure matrix; residential factor; stress; work-related factor.

Community noise is an increasing problem in urban areas worldwide (1). Short-term noise exposure is a stressor activating the sympathetic and endocrine systems, which may lead to acute changes in blood pressure and heart rate, as well as elevated levels of stress hormones (2-6). Physiological effects have been observed at high sound levels in occupational environments as well as for levels of transportation noise typically found in residential settings (7-9). It has therefore been hypothesized that exposure to transportation and occupational noise may cause permanent vascular effects (10). Epidemiological studies have shown contradicting results, but - taken together - the evidence suggests an increased risk of hypertension associated with exposure to road-traffic, aircraft, or occupational noise (11-20). In a review of residential-traffic noise exposure and hypertension, the meta-analysis showed an odds ratio (OR) of 1.034 [95\% confidence interval $(95 \% \mathrm{CI}) 1.011-1.056]$ per $5 \mathrm{dBA}$ increase of the 16-hour average road-traffic noise level $\left(\mathrm{L}_{\text {Aeq, 16h }}\right)$ range $45-75 \mathrm{dBA}(20)$. A review of occupational noise exposure and hypertension indicated a statistically significant increase in systolic blood pressure of $14.3 \mathrm{mmHg}$ (11.8-16.9) among highly exposed workers compared to workers with a low level

1 Institute of Environmental Medicine, Karolinska Institutet, Stockholm, Sweden.

2 Department of Psychology, Stockholms Universitet, Stockholm, Sweden.

3 Department of Public Health and Caring Sciences, Uppsala Universitet, Uppsala, Sweden.

4 Stress Research Institute, Stockholms Universitet, Stockholm, Sweden.

5 Department of Public Health Sciences, Karolinska Institutet, Stockholm, Sweden.

Correspondence to: Jenny Selander, Institute of Environmental Medicine, Unit of Occupational Medicine, Karolinska Institutet, Norrbacka building 3rd floor, SE-171 76 Stockholm, Sweden. [E-mail: jenny.selander@ki.se] 
of exposure (19). Myocardial infarction (MI) in relation to traffic or occupational noise exposure has been less well studied, but results of epidemiological studies show positive associations $(10,21-26)$.

Job strain is another stressor with cardiovascular effects. It may be defined as a combination of high demands and low decision latitude at work $(27,28)$. Job strain can also activate the sympathetic and endocrine systems and induce elevated blood pressure and immune system changes (29-32). Furthermore, it seems to increase sleep disturbance and reduce regenerative protective mechanisms $(31,33)$. Epidemiological studies have shown contradicting results, however, a recent review indicates an increased risk of cardiovascular disease associated with job strain (34). Thus, job strain could have a pathway similar to noise exposure in relation to cardiovascular disease, but interactions between these factors have not been investigated. The aim of the present study was to assess the risk for MI in relation to environmental and occupational noise exposure as well as job strain, including interactions between the three factors.

\section{Method}

\section{Study subjects}

The study is based on the Stockholm Heart Epidemiology Program (SHEEP) conducted in Stockholm County. This has been described in detail elsewhere (35). Briefly, the study base consisted of all men and women living in Stockholm County between 1992-1994, aged 45-70 years, and with no history of MI. The cases were selected at all emergency hospitals in Stockholm County from coronary records, hospital discharge registers, and the National Cause of Death Register of Statistics Sweden. The diagnostic criteria for case inclusion were those applied by the Swedish Association of Cardiologists and included certain symptoms, specified changes in blood and/or electrocardiogram (ECG) or myocardial necrosis detected at autopsy that could be related to the relevant time of disease onset (36). We included only subjects with first-time MI events by checking the hospital discharge registry from 1975 and onwards. Controls were randomly selected from the study base within two days of the case event matched on age, gender, and hospital catchment area. Each potential control was also checked for previous MI events in the hospital discharge register. As much as five controls per case were originally sampled in order to quickly replace one control with another in case of non-response. In total, 5452 study subjects were included: 2246 cases and 3206 controls. In this group, the questionnaire response rate among cases was $72 \%$ for women and $81 \%$ for men. The corresponding rates for controls were $70 \%$ and $75 \%$.
Our sample comprised the 3848 subjects who answered all crucial questions regarding job strain as well as cardiovascular risk factors and were included in the occupational noise assessment. Individuals with an information gap in their address history of $>5$ years since 1970 or who had lived outside Stockholm County for $>5$ years were excluded $(\mathrm{N}=401)$. This generated 3447 study subjects (1414 cases and 2033 controls). In order to minimize imprecision in the traffic-noise exposure assessment, all participants living within 200 meters of a railway track were excluded $(\mathrm{N}=397)$, leaving 3050 participants (1252 cases and 1798 controls) in the study.

\section{Questionnaire information}

The SHEEP questionnaire, distributed in 1992-1994, focused on a large set of potential risk factors for MI, including the physical and psychosocial work environment, and social and lifestyle factors, such as smoking and physical activity. For fatal cases, the questionnaire was answered by next-of-kin ( $\mathrm{N}=338)$. A supplementary telephone interview was conducted to reduce nonresponse and missing data. A special health examination was carried out on hospitalized cases and their controls in order to obtain data on various biological parameters related to cardiovascular disease. The biological variables for analysis were primarily based on data from the health examination, but some (eg, body mass index) were supplemented with questionnaire data for subjects not participating in the clinical testing.

Job strain was measured by the Swedish version (DCQ) of Karasek's Job Content Questionnaire (27), presented in more detail in a publication by Karasek \& Theorell (33). DCQ has five questions about psychological demands and six questions about decision latitude. Each question has four response categories ranging from "never" to "almost always", and the demand and decision latitude scores respectively are based on simple additions of these points. The score for demand is then divided by the score for decision latitude, and job strain is dichotomized as $>/<75^{\text {th }}$ percentile of the resulting distribution of the ratio. This model (upper ratio quartile) has been previously used in the SHEEP study and is described in detail elsewhere $(37,38)$. For separate analysis of decision latitude and psychological demand, the sum score were dichotomized at the $25^{\text {th }}$ percentile for decision latitude and $75^{\text {th }}$ percentile for psychological demands.

Physical inactivity was determined from questions on conditions at work and home, as well as on leisure-time activities. Subjects who reported inactive leisure time, including only occasional walks, during the last 5-10 years were categorized as being physically inactive.

Smoking habits were classified into 5 categories: never-smokers, ex-smokers, and current smokers (smok- 
ing $1-10,11-20$, or $>20 \mathrm{~g}$ of tobacco daily as an average for the period during which the subject had been smoking). Subjects who had never smoked regularly for $>1$ year were classified as never-smokers. Subjects who had stopped smoking for $>2$ years before inclusion were classified as ex-smokers. Subjects who smoked at the time of inclusion in the study or who had stopped smoking for $<2$ years were classified as smokers.

Socioeconomic status was determined from questions regarding professional background according to a Swedish socioeconomic index classification of occupations (39). A three-level variable was constructed, including blue-collar workers, and low- and high-level white-collar workers. The most recent working period before inclusion in the study was considered for the classification (35).

\section{Noise and air pollution exposure assessment}

The road-traffic sound level was assessed for all addresses of each study subject from 1970 until the subject entered the study in 1992-1994. For incomplete addresses, additional information was gathered from national registers or from parish records. For each address, the 24-hour average sound level $\left(\mathrm{L}_{\text {Aeq,24h }}\right)$ from road-traffic was calculated according to a simplified version of the Nordic prediction method (40). The input parameters were distance and angles to roads and the number and speed of vehicles on each road. The angles took into account shielding buildings $2 \mathrm{~m}$ above ground. We obtained traffic information from the municipalities, and maps and area photos were used to measure distance and angles from the subject's most exposed facade to the three nearest roads. Contributions of distant large roads ( $>20000$ vehicles) were assessed separately, using the same method but ignoring effects of shielding buildings. The final exposure estimate combined the levels from distant and nearby roads. The noise assessment is described in detail elsewhere (41). In our analyses, the variable was dichotomized at the $75^{\text {th }}$ percentile (51.8 dBA).

We used a job exposure matrix (JEM) to assess occupational noise exposure. The matrix is described in detail elsewhere (42). Briefly, the JEM was derived from measurements performed at occupational medicine clinics and occupational health services units in Sweden during the period 1970-2004. The JEM included 320 occupations and was based on up to 35 different measurements per occupation. In case of missing data, an expert judgment was performed in coherence with the relevant literature. Estimated exposure for each occupation of the study subjects was categorically coded as $<75,75-84$, or $\geq 85 \mathrm{~dB}\left(\mathrm{~L}_{\text {Aeq,8h }}\right)$ based on the consensus of three occupational hygienists. We used the JEM together with questionnaire information on type and duration of occupation to calculate the level and duration of each subject's occupational noise exposure. Subjects were classified as being noise exposed if they had an occupational exposure $>75 \mathrm{dBA}$ for $>1$ year.

Assessment of air pollution exposure was based on a methodology used in several epidemiological studies in Stockholm (43-45). Briefly, levels of different air pollutants were estimated from databases including historical information on emissions from road traffic and residential heating in Stockholm County back to 1960 . Combining the emission databases with dispersion models made it possible to estimate the geographical distribution of air pollution levels (annual averages) throughout the county with a resolution down to $25 \times 25$ meters in urban areas. For this study, the traffic-generated $\mathrm{NO}_{2}$ during 1970 to $1992-1994$ was used as an indicator of the individual long-term exposure to traffic-related air pollution at the home address. All exposure assessments were performed blinded to case-control status.

\section{Statistical analysis}

OR and $95 \%$ CI were calculated using unconditional logistic regression analyses. Interaction effects were calculated on the additive scale (46). Trend tests were performed assuming a linear increase across categorical variables. Regression coefficients were adjusted for the matching variables age (five categories), sex and catchment area (ten categories) and for a number of covariates. Each of a set of potential cofounders was evaluated against a preliminary multivariate logistic regression model, predicting MI from road-traffic noise exposure and matching variables. A covariate was selected if the inclusion of this variable in the preliminary model changed the OR for noise exposure by $>10 \%$. In addition, a web of causation was constructed to identify possible additional confounders and intermediate factors in the causal chain. The covariates included in the fully adjusted regression model were physical activity (dichotomous), socioeconomic status (three categories) and smoking (five categories). We also adjusted for air pollution (continuous), although this changed the regression coefficient for road-traffic noise exposure by only $7 \%$. On the other hand, diabetes was not included as a covariate in the final model, despite the fact that it changed the estimate by $10 \%$, because it may constitute a step in the causal chain between noise exposure and MI. All statistical analyses were performed with STATA 11.0 (Stata Corp, College Station, TX, USA).

\section{Ethics}

Karolinska Institutet's ethical committee approved the original study and the supplementary questionnaire, in accordance with the Declaration of Helsinki of the World Medical Association. 


\section{Results}

Table 1 shows the distribution of various MI risk factors among controls in relation to road-traffic noise exposure. The road-traffic noise-exposed controls included slightly more women and were slightly older than the low exposure group. In addition, they were less physically active and had a higher prevalence of diabetes. As expected, air pollution was strongly related to road-traffic noise exposure. There were no marked differences in the distribution of sex, age, or hospital catchment area between those responding and not responding to the questionnaire or between those excluded and included in the analyses (data not shown).

As is evident in table 2, an association with MI was seen for job strain (OR 1.39, 95\% CI 1.17-1.65). For road-traffic noise, an increased OR of 1.23 (95\% CI 1.011.51) was observed among participants exposed above the $75^{\text {th }}$ percentile. A non-significant increase was found for occupational noise exposure $>75 \mathrm{dBA}$ (OR 1.17, 95\% CI 0.98-1.41), while an analysis restricted to blue-collar workers showed an OR of 1.37 (95\% CI 1.00-1.88).

Participants exposed to road-traffic and occupational noise displayed an increased risk of MI (OR 1.44, 95\% CI 1.07-1.95) (figure 1). Among subjects exposed to road-traffic or occupational noise in combination with job strain, a tendency towards an interaction exceeding additivity was suggested (OR 1.83, 95\% CI 1.33-2.52, and OR 1.72, 95\% CI 1.32-2.24, respectively), but this was not statistically significant.

Figure 2 shows associations for risk of MI when exposed to one, two, or three of the noise and job strain factors under study. The OR were 1.16 (95\% CI 0.97-1.40), 1.57 (95\% CI 1.24-1.98) and 2.27 (95\% CI 1.41-3.64) among participants exposed to one, two, or three factors, respectively, compared to those unexposed to all three factors, corresponding to a statistically significant trend (OR 1.27, 95\% CI 1.14-1.41). A total of $20 \%$ of the controls were exposed to two or three factors in combination.

Separate interaction analysis regarding psychological demands in combination with residential road-traffic noise showed an OR of 1.11 (95\% CI 0.88-1.42) for only

Table 1. Selected characteristics of population controls in Stockholm 1992-1994 by job strain, road-traffic and occupational noise exposure.

\begin{tabular}{|c|c|c|c|c|c|c|c|c|c|c|c|c|}
\hline \multirow[t]{3}{*}{ Variables } & \multicolumn{4}{|c|}{ Road traffic noise } & \multicolumn{4}{|c|}{ Occupational noise } & \multicolumn{4}{|c|}{ Job strain } \\
\hline & \multicolumn{2}{|c|}{$<75^{\text {th }}$ percentile } & \multicolumn{2}{|c|}{$\geq 75^{\text {th }}$ percentile } & \multicolumn{2}{|c|}{$<75 \mathrm{~dB}$} & \multicolumn{2}{|c|}{$\geq 75 \mathrm{~dB}$} & \multicolumn{2}{|c|}{ No } & \multicolumn{2}{|c|}{ Yes } \\
\hline & $\mathrm{N}$ & $\%$ & $\mathrm{~N}$ & $\%$ & $\mathrm{~N}$ & $\%$ & $\mathrm{~N}$ & $\%$ & $\mathrm{~N}$ & $\%$ & $\mathrm{~N}$ & $\%$ \\
\hline Female gender & 454 & $32^{a}$ & 150 & 39 a & 440 & $38^{a}$ & 165 & $25^{a}$ & 411 & $30^{a}$ & 194 & $44^{a}$ \\
\hline \multicolumn{13}{|l|}{ Age (years) } \\
\hline $45-50$ & 154 & 11 & 29 & 7 & 100 & $9^{a}$ & 83 & $13^{a}$ & 134 & 10 & 49 & 11 \\
\hline $51-55$ & 199 & 14 & 47 & 12 & 143 & 12 & 103 & 16 & 197 & 15 & 49 & 11 \\
\hline $56-60$ & 293 & $21^{a}$ & 61 & $16^{a}$ & 216 & 19 & 138 & 21 & 271 & 20 & 83 & 19 \\
\hline $61-65$ & 318 & 23 & 80 & 21 & 237 & 21 & 161 & 25 & 277 & $20^{a}$ & 121 & $27^{a}$ \\
\hline $66-70$ & 446 & $32^{a}$ & 171 & $44^{\mathrm{a}}$ & 450 & $39^{a}$ & 169 & $26^{a}$ & 478 & 35 & 141 & 32 \\
\hline \multicolumn{13}{|l|}{ Smoking } \\
\hline Never & 592 & 42 & 148 & 38 & 509 & $44^{\text {a }}$ & 231 & $35^{a}$ & 532 & 39 a & 208 & $47^{\mathrm{a}}$ \\
\hline Former & 432 & 31 & 118 & 30 & 363 & 32 & 188 & 29 & 430 & 32 & 121 & 27 \\
\hline Current (1-10 g/day) & 78 & 6 & 25 & 6 & 67 & 6 & 36 & 6 & 80 & 6 & 23 & 5 \\
\hline Current (11-20 g/day) & 231 & 16 & 74 & 19 & 153 & $13^{a}$ & 153 & $23^{a}$ & 236 & 17 & 70 & 16 \\
\hline Current (>20 g/day) & 77 & 5 & 23 & 6 & 54 & $5^{a}$ & 46 & $7^{a}$ & 79 & 6 & 21 & 5 \\
\hline Physical inactivity & 498 & $35^{a}$ & 161 & $41^{a}$ & 408 & 36 & 253 & 39 & 500 & 37 & 161 & 36 \\
\hline Diabetes & 84 & $6^{a}$ & 38 & $10^{a}$ & 70 & 6 & 52 & 8 & 88 & 6 & 34 & 8 \\
\hline \multicolumn{13}{|l|}{ Socioeconomic position } \\
\hline Blue-collar & 435 & 31 & 125 & 32 & 168 & $15^{a}$ & 392 & $60^{a}$ & 390 & 29 a & 170 & $38^{a}$ \\
\hline Low-level white-collar & 281 & 20 & 85 & 22 & 278 & $24^{a}$ & 88 & 13 & 254 & 19 & 112 & $25^{a}$ \\
\hline High-level white-collar & 694 & 49 & 178 & 46 & 698 & $61^{\text {a }}$ & 174 & $27^{a}$ & 711 & $52^{a}$ & 161 & $36^{a}$ \\
\hline Body mass index $\geq 27$ kg/m² & 421 & 30 & 121 & 31 & 315 & $27^{\text {a }}$ & 228 & $35^{\text {a }}$ & 397 & 29 & 146 & 33 \\
\hline Job strain b & 345 & 24 & 98 & 25 & 267 & 23 & 176 & 27 & & & & \\
\hline Occupational noise exposure ${ }^{c}$ & 494 & 37 & 126 & 35 & & & & & 478 & 35 & 176 & 40 \\
\hline Residential road-traffic noise ${ }^{d}$ & & & & & 255 & 22 & 134 & 20 & 291 & 21 & 98 & 22 \\
\hline High traffic-related air pollution e & 183 & $14^{\mathrm{a}}$ & 217 & $61^{\text {a }}$ & 291 & 26 & 142 & 22 & 321 & 24 & 112 & 26 \\
\hline Hypertension & 364 & 27 & 98 & 26 & 312 & 27 & 170 & 26 & 360 & 27 & 122 & 28 \\
\hline Railway noise exposure & 147 & $9^{a}$ & 88 & $18^{a}$ & 142 & 11 & 93 & 12 & 173 & 11 & 62 & 12 \\
\hline
\end{tabular}

a $<0.05 \mathrm{P}$-value in chi test of statistical difference between groups.

${ }^{b}$ Job strain was defined as $>75^{\text {th }}$ percentile in an overall sum score where psychological demand was divided by decision latitude.

c $\geq 75 \mathrm{~dB}$ for $\geq 1$ year during the exposure period from 1970 to 1992-1994.

d Time-weighted average of road-traffic sound levels ( $\mathrm{L}$ Aeq, $24 \mathrm{~h}$ ) for each of the subject's addresses during the exposure period (from 1970 to 1992-1994).

e Estimated time-weighted exposure to air pollution from traffic at residential addresses during the exposure period using $\mathrm{NO}_{2}$ as indicator. The $75^{\text {th }}$ percentile was used for classification into high/low exposure. 
Table 2. Logistic regression analysis for job strain and road-traffic and occupational noise exposure in association with myocardial infarction. Data from a case-control study conducted in Stockholm County 1992-1994 ( $\mathrm{N}=3050)$. [OR=odds ratio; 95\% Cl=95\% confidence interval; $\mathrm{L}_{\text {Aeq24h }}=24$-hour average sound level.]

\begin{tabular}{|c|c|c|c|c|c|}
\hline \multirow[t]{2}{*}{ Exposure } & \multirow{2}{*}{$\frac{\text { Exposed }}{\mathrm{N}}$} & \multicolumn{2}{|c|}{ Crude } & \multicolumn{2}{|c|}{ Adjusted a } \\
\hline & & $\mathrm{OR}$ & $95 \% \mathrm{Cl}$ & $\mathrm{OR}$ & $95 \% \mathrm{Cl}$ \\
\hline \multicolumn{6}{|l|}{$\begin{array}{l}\text { Road-traffic noise } \\
\mathrm{dB}\left(\mathrm{L}_{\text {Aeq24h }}\right)\end{array}$} \\
\hline $\begin{array}{l}>75^{\text {th }} \text { percentile } \\
(51.8 \mathrm{dBA})\end{array}$ & 708 & 1.17 & $1.01-1.36$ & 1.23 & $1.01-1.51$ \\
\hline Job strain & & & & & \\
\hline$>75^{\text {th }}$ percentile ${ }^{b}$ & 836 & 1.46 & $1.26-1.69$ & 1.39 & $1.17-1.65$ \\
\hline $\begin{array}{l}\text { Occupational noise } \\
>75 \mathrm{dBA}\end{array}$ & 1219 & 1.35 & $1.18-1.55$ & 1.17 & $0.98-1.41$ \\
\hline
\end{tabular}

${ }^{a}$ Analysis were adjusted for age, sex, hospital catchment area, physical inactivity, smoking, air pollution and socioeconomic position.

${ }^{b}$ Job strain was defined as $>75^{\text {th }}$ percentile in an overall sum score where psychological demand was divided by decision latitude.

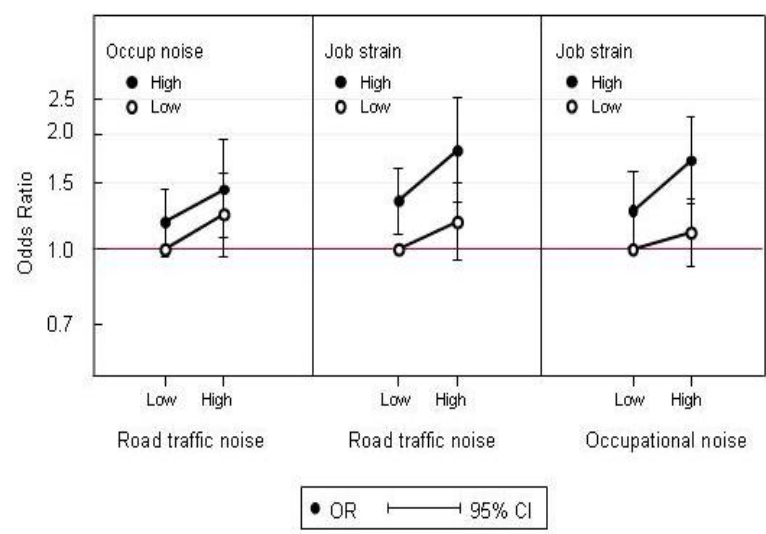

Figure 1. Associations between road-traffic noise exposure $\left(>/<75^{\text {th }}\right.$ percentile $\left.51.8 \mathrm{~dB} \mathrm{~L}_{\text {Aeq,24h }}\right)$, occupational noise exposure $(>/<75 \mathrm{~dB}$ $\left.L_{\text {eeq,8n }}\right)$ and job strain $\left(>l<\right.$ the $75^{\text {th }}$ percentile in a ratio, where decision latitude was divided by psychological demand) in relation to myocardial infarction in a case-control study from Stockholm. All models were adjusted for matching variables (age, sex and catchment area) as well as for physical inactivity, smoking, socioeconomic position and air pollution. [OR=0dds ratio; $95 \% \mathrm{Cl}=95 \%$ confidence interval]

traffic noise, OR 1.18 (95\% CI 0.99-1.42) for only psychological demands, and OR 1.77 (95\% CI 1.31-2.40) for both. For psychological demands in combination with occupational noise exposure, an OR of 1.11 (95\% CI CI 0.90-1.38) for only occupational noise, OR 1.18 (95\% CI $0.96-1.45$ ) for only psychological demands and OR 1.57 (95\% CI 1.21-2.03) for both was shown. For decision latitude, an increased risk of MI was shown for a combination of decision latitude and residential traffic noise with OR 1.19 (95\% CI $0.94-1.50)$ for only residential traffic noise, OR 1.45 (95\% CI 1.17-1.79) for only deci-

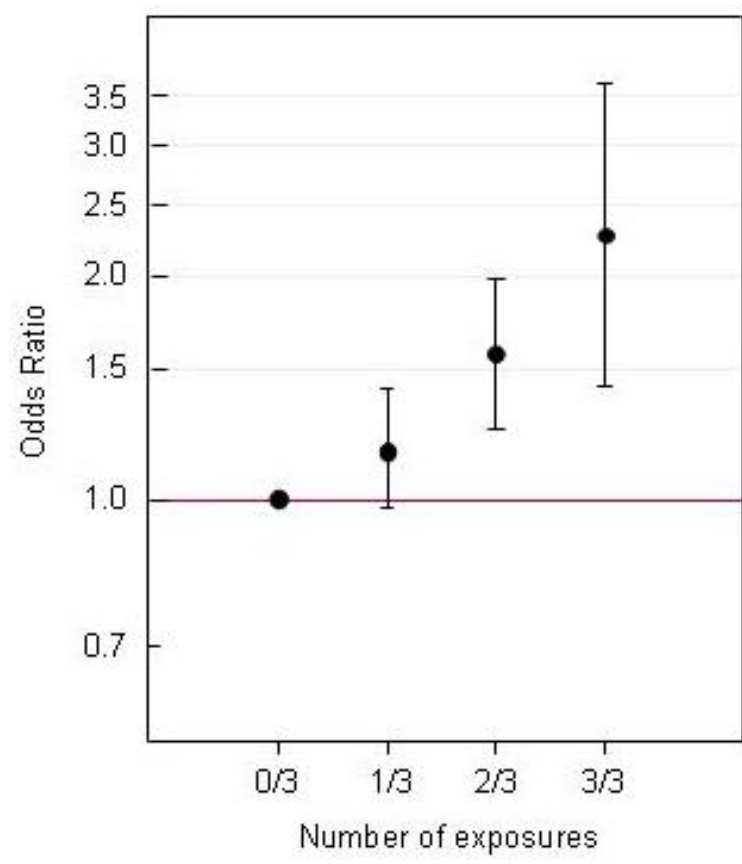

- OR $\longmapsto 95 \% \mathrm{Cl}$

Figure 2. Associations for myocardial infarction among individuals with or without road-traffic noise $\left(>/<75^{\text {th }}\right.$ percentile $\left.51.8 \mathrm{~dB} L_{\text {Aeq, 24h }}\right)$, occupational noise $\left(>/<75 \mathrm{~dB} \mathrm{~L}_{\text {Aeq, } 8 \mathrm{~h}}\right)$ and job strain $\left(>/<\right.$ the $75^{\text {th }}$ percentile in a ratio, where decision latitude was divided by psychological demand) in a case-control study from Stockholm. The first category $0 / 3$ is the reference group with low exposure to all 3 factors. The categories $1 / 3$ $2 / 3$ and $3 / 3$ contain study participants exposed to 1,2 or all 3 of the factors investigated. All models were adjusted for matching variables (age, sex and catchment area) as well as for physical inactivity, smoking, socioeconomic position, and air pollution. [OR=odds ratio; $95 \%$ $\mathrm{Cl}=95 \%$ confidence interval]

sion latitude, and OR 2.04 (95\% CI 1.46-2.85) for both. An increased risk of MI was also shown for decision latitude in combination with occupational noise, with OR 1.09 (95\% CI $0.89-1.34)$ for only occupational noise, OR 1.40 (95\% CI 1.07-1.84) for only decision latitude, and OR 1.76 (95\% CI 1.35-2.30) for both.

\section{Discussion}

\section{Principal findings}

Our findings support the hypothesis that the risk of MI increases with multiple stress-related exposures. This increase was observed among those exposed to either environmental or occupational noise sources or a combination of noise and job strain. Each of the exposures under 
study has been related to MI in earlier investigations. For job strain, some studies have indicated an increase in risk of MI similar to our findings (34). For road-traffic and occupational noise, earlier studies have shown a small increase in risk of MI and hypertension $(10,11,24,41)$. These studies mainly focused on higher noise levels, and it is of interest that our associations were found for substantially lower noise levels, which affect a greater part of the population. In our study, $20 \%$ of the controls had exposures to two or three of the assessed factors.

\section{Strengths and limitations of study}

A major strength of the present study was the extensive assessment of road-traffic and occupational noise exposure and job strain. The detailed road-traffic noise exposure assessment for all addresses since 1970 made it possible to estimate the exposure for a longer period (22-24 years) than in previous longitudinal studies (10). The extensive JEM covering 320 occupations and based on up to 35 different measurements per occupation enabled a thorough exposure classification of occupational noise exposure (42). A well-defined and validated method of assessing job strain used in many earlier studies was employed (37). A further strength was that our study covered estimated risks at lower levels of road-traffic and occupational noise exposure than other investigations, making the results applicable for a greater part of the population. In comparison, the Berlin studies regarding road traffic evaluated risk in comparison to a $\leq 60 \mathrm{~dB}$ $\left(\mathrm{L}_{\text {Aeq,6-22h }}\right)$ exposure category and a study from British Columbia regarding occupational noise exposure used $><<5 \mathrm{dBA}(22,24)$. Our results suggest that an adverse effect of noise on MI may exist already at lower levels. Another strength of our study is the extensive information available on a large number of cardiovascular risk factors, such as smoking, socioeconomic position, physical inactivity, and air pollution. This enabled careful control of confounding and assessment of interactions. Diabetes was not included as a covariate in the regression analysis as it may constitute an intermediate step in the causal chain between noise exposure and cardiovascular disease. Some studies suggest that stress is related to development of the metabolic syndrome $(47,48)$ and might thus also affect diabetes occurrence, which is a risk factor for cardiovascular disease. However, the estimates in our study with regard to noise and MI did not change markedly when including diabetes in the model.

Misclassification of disease would probably be negligible in the present study given the strict diagnostic criteria, the high reliability of case identification, and the low probability of selection or recall bias $(36,49,50)$. However, misclassification of exposure should be considered. Some of our data on road-traffic volume did not cover the relevant time period and exposure variation related to the floor of apartment buildings was not considered. We used a simplified assessment model, which had high validity, but should be less precise than more detailed methods (40). The resulting biases would probably be unrelated to disease outcome and lead to attenuation of the effect estimates. Moreover, only residential exposure was considered although road-traffic noise is common in other places as well, such as workplaces and recreational areas. This imprecision in assessment of total road-traffic noise exposure may further have attenuated the estimated effect. Misclassification of exposure should also be considered regarding occupational noise exposure. The JEM is a simplified assessment and, in order to obtain a more precise estimation, an individual assessment of occupational noise exposure has to be performed. However, a similar approach has been used in earlier studies and found to be of high validity. (51). Any possible imprecision in exposure assessment would probably primarily lead to attenuation of the effect estimates. Information on job strain is based on questionnaire data after disease onset and can therefore be affected by recall bias. Such bias may be related to disease outcome and could therefore have the potential to affect the estimates away from null. However, the two variables in the job strain measurement (ie, psychological demands and decision latitude) have been validated by the use of both inferred and selfreported data. The sensitivity was poor but the specificity was high: $84 \%$ for both cases and referents with regard to decision latitude and $83 \%$ and $82 \%$ for cases and referents for psychological demand. These results indicate that a recent MI does not substantially influence the self-ratings of demand and decision latitude (38). Separate analysis on psychological demand and decision latitude indicate increased risks for $\mathrm{MI}$ in combination with traffic and occupational noise in the same way as the combined job strain measure. However, the increase in risk appeared more pronounced for decision latitude.

The risk estimates for MI in relation to residential and occupational noise exposure appeared to be of similar magnitude, even though residential noise levels are considerably lower than those in occupational settings. There may be several explanations for this. First, traffic noise at home can affect the individual differently than occupational noise since it may disturb recovery and sleep. In a recent Finnish study, residential traffic noise $>55 \mathrm{dBA}$ at the façade affected sleep and increased the risk of insomnia symptoms (52). In a subgroup with higher scores for anxiety, an increase in risk of insomnia symptoms was shown already at $>50 \mathrm{dBA}$. These noise levels are equal to the residential noise exposure assessed in this study. Sleep disturbance is associated with an increased risk of cardiovascular disease (53). In a recent field study, traffic noise was associated with an instant increase in blood pressure during sleep, even at such low levels as $>35 \mathrm{dBA}$ inside the bedroom (6). 
Second, misclassification of exposure is probably more pronounced in the occupational assessment since we related the occupational history to a JEM that classifies occupations in only three different categories $<75,75-85$, $>85 \mathrm{dBA}$ based on job titles and work tasks. However, no actual measurements or calculations were made at the workplaces of the participants; instead the exposure was based on an average level of measured noise in similar workplaces. In addition, subjects were dichotomously classified as being noise-exposed if they had had an occupational exposure $>75 \mathrm{dBA}$ for $>1$ year in the last 20 years, and the crude classification may lead to diluted associations. In comparison, the residential traffic data was based on calculations for each address of the participants during the last 20 years, where measurements of distance and angles from the building to the nearest roads combined with data on traffic flow, speed contributed to a fairly accurate measure of exposure in $1 \mathrm{dBA}$ resolution. In addition, a time-weighted average was used to combine noise exposure from different addresses.

Residual confounding may also be a problem. For example, air pollution has been linked to cardiovascular outcomes (54); since air pollution and noise from traffic are correlated, a great effort was made in this study to accurately assess residential exposure to air pollution from traffic. Adjusting for air pollution in the analysis did not change the risk estimates markedly for the association between traffic-noise exposure and MI, mainly because the association between traffic-related air pollution and MI was weak (44).

Risk estimates related to road-traffic noise were more clearly elevated after exclusion of subjects exposed to railway noise. This suggests that the association in the full sample may have been diluted due to misclassification of total noise exposure from traffic. Although studies on railway noise and cardiovascular endpoints are lacking, adverse effects of railway noise, such as annoyance and sleep disturbance, are well-documented $(55,56)$. Unfortunately, we lacked sufficient precision in the estimation of exposure to noise from railways, making it difficult to assess exposure-response relationships.

\section{Implications and future research}

Our results indicate that joint effects of different noise sources and/or job strain markedly increases the risk of MI. As many as $1 / 5$ of the participants were exposed to $\geq 2$ of these factors, thus the excess risk affects a noticeable part of the population. The results may thus be important for prioritization of preventive measures regarding MI. Further studies are needed to shed light on interaction effects, preferably using prospective designs. It would also be of interest to analyze dose-response relationships. However, both a prospective approach and dose-response analyses would require very large population samples.

\section{Acknowledgments}

This study was financed by the Swedish Council for Working Life and Social Research (FAS), the Swedish Road Administration, and the Emission Research Program (EMFO), all of which are government-supported authorities with no commercial financial interests. The financiers have not been active in any part of the study (study design, the collection, the analysis, the interpretation of data, writing the article, in decision to submit the article). The researchers have total independence from funders.

All authors have completed the unified competing interest form at www.icmje.org/coi_disclosure.pdf (available on request from the corresponding author) and declare that JS, GB, MN, JH, TT, PW and GP have support from Karolinska Institutet, Stockholm University, and Uppsala University for the submitted work. JS, GB, MN, JH, TT, PW and GP have no relationship with any company that might have an interest in the submitted work in the previous 3 years; their spouses, partners, or children have no financial relationship that may be relevant to the submitted work; and JS, GB, MN, JH, TT, PW and GP have no non-financial interests that may be relevant to the submitted work.

\section{References}

1. WHO, Guidelines for Community Noise. Geneva: World Health Organisation; 2000.

2. Andren, L, Cardiovascular effects of noise. Acta Med Scand Suppl. 1982.657:1-45.

3. Andren L, Lindstedt G, Bjorkman M, Borg KO, Hansson L, Effect of noise on blood pressure and 'stress' hormones. Clin Sci. 1982;62(2):137-41.

4. Cavatorta A, Falzoi M, Romanelli A, Cigala F, Ricco M, Bruschi G, et al., Adrenal response in the pathogenesis of arterial hypertension in workers exposed to high noise levels. J Hypertens Suppl. 1987;5(5):S463-6.

5. Ising $\mathrm{H}$, Braun $\mathrm{C}$, Acute and chronic endocrine effects of noise: Review of the research conducted at the Institute for Water, Soil and Air Hygiene. Noise Health. 2000;2(7):7-24.

6. Haralabidis AS, Dimakopoulou K, Vigna-Taglianti F, Giampaolo M, Borgini A, Dudley ML, et al. Acute effects of night-time noise exposure on blood pressure in populations living near airports. Eur Heart J. 2008;29(5):658-64. http:// dx.doi.org/10.1093/eurheartj/ehn013.

7. Ising H, Michalak R. Stress effects of noise in a field experiment in comparison to reactions to short term noise exposure in the laboratory. Noise Health. 2004;6(24):1-7.

8. Marks A, Griefahn B. Associations between noise sensitivity and sleep, subjectively evaluated sleep quality, annoyance, and 
performance after exposure to nocturnal traffic noise. Noise Health. 2007;9(34):1-7. http://dx.doi.org/10.4103/14631741.34698

9. Selander J, Bluhm G, Theorell T, Pershagen G, Babisch W, Seiffert I, et al. Saliva cortisol and exposure to aircraft noise in six European countries. Environ Health Perspect. 2009;117(11):1713-7.

10. Babisch W. Transportation noise and cardiovascular risk: updated review and synthesis of epidemiological studies indicate that the evidence has increased. Noise Health. 2006;8(30):1-29. http://dx.doi.org/10.4103/14631741.32464

11. van Kempen EE, Kruize $\mathrm{H}$, Boshuizen $\mathrm{HC}$, Ameling $\mathrm{CB}$, Staatsen BA, de Hollander AE. The association between noise exposure and blood pressure and ischemic heart disease: a meta-analysis. Environ Health Perspect. 2002;110(3):307-17. http://dx.doi.org/10.1289/ehp.02110307.

12. Knipschild PV. Medical effects of aircraft noise: community cardiovascular survey. Int Arch Occup Environ Health. 1977;40(3):185-90. http://dx.doi.org/10.1007/BF01842081.

13. Rosenlund M, Berglind N, Pershagen G, Jarup L, Bluhm G. Increased prevalence of hypertension in a population exposed to aircraft noise. Occup Environ Med. 2001;58(12):769-73. http://dx.doi.org/10.1136/oem.58.12.769.

14. Eriksson C, Rosenlund M, Pershagen G, A Hilding, CG Ostenson, G Bluhm. Aircraft noise and incidence of hypertension. Epidemiology. 2007;18(6):716-21. http:// dx.doi.org/10.1097/EDE.0b013e3181567e77.

15. Knipschild P, Salle H. Road-traffic noise and cardiovascular disease. A population study in The Netherlands. Int Arch Occup Environ Health. 1979;44(1):55-9. http://dx.doi. org/10.1007/BF00381208.

16. Bluhm G, Berglind N, Nordling E, Rosenlund M. Road-traffic noise and hypertension. Occup Environ Med. 2007;64(2):122-6. http://dx.doi.org/10.1136/oem.2005.025866.

17. de Kluizenaar Y, Gansevoort RT, Miedema HM, de Jong PE. Hypertension and road-traffic noise exposure. J Occup Environ Med. 2007;49(5):484-92. http://dx.doi.org/10.1097/ JOM.0b013e318058a9ff.

18. Sbihi H, Davies HW, Demers PA. Hypertension in noise-exposed sawmill workers: a cohort study. Occup Environ Med. 2008;65(9):643-6. http://dx.doi.org/10.1136/ oem.2007.035709.

19. Tomei G, Fioravanti M, Cerratti D, Sancini A, Tomao E, Rosati MV et al. Occupational exposure to noise and the cardiovascular system: a meta-analysis. Sci Total Environ. 408(4):681-9. http://dx.doi.org/10.1016/j. scitotenv.2009.10.071.

20. van Kempen E, Babisch W. The quantitative relationship between road-traffic noise and hypertension: a meta-analysis. J Hypertens. 2012;30(6):1075-86. http://dx.doi.org/10.1097/ HJH.0b013e328352ac54.

21. Babisch W, Ising H, Gallacher JE, Sweetnam PM, Elwood PC. Traffic noise and cardiovascular risk: the Caerphilly and Speedwell studies, third phase--10-year follow up. Arch Environ Health. 1999;54(3):210-6. http://dx.doi. org/10.1080/00039899909602261.

22. Babisch W, Beule B, Schust M, Kersten N, Ising H. Traffic noise and risk of myocardial infarction. Epidemiology. 2005;16(1):33-40. http://dx.doi.org/10.1097/01. ede.0000147104.84424.24.

23. Willich SN, Wegscheider K, Stallmann M, Keil T. Noise burden and the risk of myocardial infarction. Eur Heart J. 2006;27(3):276-82. http://dx.doi.org/10.1093/eurheartj/ ehi658.

24. Davies HW, Teschke K, Kennedy SM, Hodgson MR, Hertzman C, Demers PA. Occupational exposure to noise and mortality from acute myocardial infarction. Epidemiology, 2005;16(1):25-32. http://dx.doi.org/10.1097/01. ede.0000147121.13399.bf.

25. Andersson E, Persson B, Bryngelsson IL, Magnuson A, Toren $\mathrm{K}$, Wingren G, et al. Cohort mortality study of Swedish pulp and paper mill workers-nonmalignant diseases. Scand J Work Environ Health. 2007;33(6):470-8. http://dx.doi.org/10.5271/ sjweh.1173.

26. Huss A, Spoerri A, Egger M, Roosli M. Aircraft noise, air pollution, and mortality from myocardial infarction. Epidemiology. 2010;21(6):829-36. http://dx.doi.org/10.1097/ EDE.0b013e3181f4e634.

27. Karasek RA. Job demands, job decision latitude, and mental strain:implications for job redesign. Administration Science Quarterly. 1979;24:285-307. http://dx.doi. org/10.2307/2392498.

28. Theorell T, Karasek RA. Current issues relating to psychosocial job strain and cardiovascular disease research. J Occup Health Psychol. 1996;1(1):9-26. http://dx.doi.org/10.1037/10768998.1.1.9.

29. Belkic K, Schwartz J, Schnall P, Pickering TG, Steptoe A, Marmot M, et al. Evidence for mediating econeurocardiologic mechanisms. Occup Med. 2000;15(1):117-62.

30. Alderling M, Theorell $\mathrm{T}$, de la Torre B, Lundberg I. The demand control model and circadian saliva cortisol variations in a Swedish population based sample (The PART study). BMC Public Health. 2006;6:288. http://dx.doi.org/10.1186/14712458-6-288.

31. Theorell T. On biochemical and physiological indicators of stress relevant to cardiovascular illness. Eur Heart J. 1988;9(6):705-8.

32. Theorell T. Job stress and fibrinogen. Eur Heart J. 2002;23(23):1799-801. http://dx.doi.org/10.1053/ euhj.2002.3293.

33. Theorell T, Karasek RA, Eneroth P. Job strain variations in relation to plasma testosterone fluctuations in working men--a longitudinal study. J Intern Med. 1990;227(1):31-6. http:// dx.doi.org/10.1111/j.1365-2796.1990.tb00115.x.

34. Eller NH, Netterstrom B, Gyntelberg F, Kristensen TS, Nielsen F, Steptoe A, et al. Work-related psychosocial factors and the development of ischemic heart disease: a systematic review. Cardiol Rev. 2009;17(2):83-97. http://dx.doi.org/10.1097/ CRD.0b013e318198c8e9.

35. Reuterwall C, Hallqvist J, Ahlbom A, De Faire U, Diderichsen 
F, Hogstedt C, et al. Higher relative, but lower absolute risks of myocardial infarction in women than in men: analysis of some major risk factors in the SHEEP study. The SHEEP Study Group. J Intern Med. 1999;246(2):161-74. http://dx.doi. org/10.1046/j.1365-2796.1999.00554.x.

36. Stockholm County Council. Behandlingsprogram för Danderyds sjukhus, Ersta sjukhus, Huddinge sjukhus, Karolinska sjukhuset, Löwenströmska sjukhuset, Nacka sjukhus, Norrtälje sjukhus, Sabbatsbergs sjukhus, S:t Görans sjukhus, Södersjukhuset, Södertälje sjukhus [Treatment program for Danderyds hospital, Ersta hospital, Huddinge hospital, Karolinska hospital, Löwenströmska hospital, Nacka hospital, Norrtälje hospital, Sabbatsbergs hospital, St Görans hospital, Söderhospital, Södertälje hospital]. Stockholm: Stockholm County Council; 1990.

37. Hallqvist J, Diderichsen F, Theorell T, Reuterwall C, Ahlbom A. Is the effect of job strain on myocardial infarction risk due to interaction between high psychological demands and low decision latitude? Results from Stockholm Heart Epidemiology Program (SHEEP). Soc Sci Med. 1998;46(11):1405-15. http:// dx.doi.org/10.1016/S0277-9536(97)10084-3.

38. Theorell T, Tsutsumi A, Hallquist J, Reuterwall C, Hogstedt C, Fredlund P, et al. Decision latitude, job strain, and myocardial infarction: a study of working men in Stockholm. The SHEEP Study Group. Stockholm Heart epidemiology Program. Am J Public Health. 1998;88(3):382-8. http://dx.doi.org/10.2105/ AJPH.88.3.382.

39. Statistics Sweden. Swedish Socioeconomic Classification, Reports on Statistical Coordination. Stockholm: Statistics Sweden; 1982.

40. Swedish EPA. Vägtrafikbuller. Nordisk beräkningsmodell, reviderad 1996 [Road-traffic noise. The Nordic calculation Method, revised 1996]. Stockholm: Swedish EPA; 1996.

41. Selander J, Nilsson ME, Bluhm G, Rosenlund M, Lindqvist M, Nise G, et al. Long-Term Exposure to Road-traffic noise and Myocardial Infarction. Epidemiology. 2009;20(2):272-9. http://dx.doi.org/10.1097/EDE.0b013e31819463bd.

42. Edwards CG, Schwartzbaum JA, Nise G, Forssen UM, Ahlbom A, Lonn S, et al. Occupational noise exposure and risk of acoustic neuroma. Am J Epidemiol. 2007;166(11):1252-8. http://dx.doi.org/10.1093/aje/kwm217.

43. Nyberg F, Gustavsson P, Jarup L, Bellander T, Berglind N, Jakobsson R, et al. Urban air pollution and lung cancer in Stockholm. Epidemiology. 2000;11(5):487-95. http://dx.doi. org/10.1097/00001648-200009000-00002.

44. Rosenlund M, Berglind N, Pershagen G, Hallqvist J, Jonson $\mathrm{T}$, Bellander T, Long-term exposure to urban air pollution and myocardial infarction. Epidemiology. 2006;17(4):383-90. http://dx.doi.org/10.1097/01.ede.0000219722.25569.0f.

45. Bellander T, Berglind N, Gustavsson P, Jonson T, Nyberg F, Pershagen $\mathrm{G}$, et al. Using geographic information systems to assess individual historical exposure to air pollution from traffic and house heating in Stockholm. Environ Health Perspect. 2001;109(6):633-9. http://dx.doi.org/10.1289/ ehp.01109633.

46. Andersson T, Alfredsson L, Kallberg H, Zdravkovic S, Ahlbom
A. Calculating measures of biological interaction. Eur $\mathrm{J}$ Epidemiol. 2005;20(7):575-9. http://dx.doi.org/10.1007/ s10654-005-7835-x.

47. Ljung T, Holm G, Friberg P, Andersson B, Bengtsson BA, Svensson J, et al. The activity of the hypothalamicpituitary-adrenal axis and the sympathetic nervous system in relation to waist/hip circumference ratio in men. Obes Res. 2000;8(7):487-95. http://dx.doi.org/10.1038/oby.2000.61.

48. Kyrou I, Chrousos GP, Tsigos C. Stress, visceral obesity, and metabolic complications. Ann N Y Acad Sci. 2006;1083:77110. http://dx.doi.org/10.1196/annals.1367.008.

49. Hammar N, Nerbrand C, Ahlmark G, Tibblin G, Tsipogianni A, Johansson S, et al. Identification of cases of myocardial infarction: hospital discharge data and mortality data compared to myocardial infarction community registers. Int J Epidemiol. 1991;20(1):114-20. http://dx.doi.org/10.1093/ije/20.1.114.

50. Alfredsson L, Spetz CL, Åkesson LO, Hammar N, Kahan T, Ysberg AS. Värdering av diagnoskvalitet för akut hjärtinfarkt $i$ tre svenska län 1995 [Assessment of the Quality of Diagnosis of Acute Myocardial Infarction in Three Swedish Counties 1995]. Stockholm: The Swedish National Board of Health and Welfare; 1997.

51. Davies HW, Teschke K, Kennedy SM, Hodgson MR, Demers PA. A retrospective assessment of occupational noise exposures for a longitudinal epidemiological study. Occup Environ Med. 2009;66(6):388-94. http://dx.doi.org/10.1136/ oem.2008.040881.

52. Halonen JI, Vahtera J, Stansfeld S, Yli-Tuomi T, Salo P, Pentti J, et al. Associations between Nocturnal Traffic Noise and Sleep: the Finnish Public Sector Study. Environ Health Perspect. 2012 Aug 7 [Epub ahead of print]. http://dx.doi. org/10.1289/ehp.1205026.

53. Grandner MA, Jackson NJ, Pak VM, Gehrman PR. Sleep disturbance is associated with cardiovascular and metabolic disorders. J Sleep Res. 2012;21(4):427-33. http://dx.doi. org/10.1111/j.1365-2869.2011.00990.x.

54. Brook RD, Rajagopalan S, Pope CA, Brook JR, Bhatnagar A, Diez-Roux AV, et al. Particulate matter air pollution and cardiovascular disease: An update to the scientific statement from the American Heart Association. Circulation. 2010;121(21):2331-78. http://dx.doi.org/10.1161/ CIR.0b013e3181dbece1.

55. Miedema HM, Oudshoorn CG. Annoyance from transportation noise: relationships with exposure metrics DNL and DENL and their confidence intervals. Environ Health Perspect. 2001;109(4):409-16. http://dx.doi.org/10.1289/ ehp.01109409.

56. Miedema HM, Vos H. Associations between self-reported sleep disturbance and environmental noise based on reanalyses of pooled data from 24 studies. Behav Sleep Med. 2007;5(1):120. http://dx.doi.org/10.1207/s15402010bsm0501_1.

Received for publication: 2 March 2012 